\title{
COMUNICAÇÃO
}

\section{OCORRÊNCIA DE TRANSMISSÃO AUTÓCTONE DE LEISHMANIOSE VISCERAL EM MATO GROSSO}

\author{
Márcia Hueb, Sandra Breder Assis, Eliane Elisa Donadel Guimarães, \\ Daltro Lemos Rosa e Cor Jésus Fernandes Fontes
}

\begin{abstract}
A leishmaniose visceral (LV) no Brasil tem se mostrado em franca expansão, tanto pelo aumento do número absoluto de casos como pela tendência em se expandir geograficamente ${ }^{679}$.

O Estado de Mato Grosso, antes de sua divisão em 1979, apresentava transmissão de IV na região de Corumbá, que se mantém até hoje. Essa região, após a separação dos estados, ficou localizada no então recém-criado Mato Grosso do Sul. O novo Estado de Mato Grosso, apesar de endêmico para muitas doenças tropicais como malária, paracoccidioidomicose, leishmaniose tegumentar, entre outras, não tem registro da ocorrência de casos autóctones de calazar ${ }^{9}$.
\end{abstract}

No período de 1992 a 1994 , quatro casos de $\mathrm{LV}$ foram diagnosticados e tratados no Hospital da Universidade Federal de Mato Grosso, em Cuiabá. Após investigação sobre procedência e história migracional dos pacientes, concluiu-se por tratar-se de transmissão autóctone da doença no Estado.

O primeiro caso foi de um paciente masculino de 49 anos, natural de São Paulo, e residente em Mato Grosso há 12 anos, não se tendo ausentado do Estado nesse período. Apresentava quadro de febre, emagrecimento, hepatoesplenomegalia, adenomegalia, lesôes cutâneas, pancitopenia e hipergamaglobulinemia. O diagnóstico foi feito pelo achado do protozoário em medula óssea, linfonodos e pele ao exame direto. O paciente evoluiu bem com o tratamento convencional.

O segundo paciente era uma mulher de 39 anos, natural e procedente de Santo Antônio

Departamentos de Clínica Médica e Pediatria - Universidade Federal de Mato Grosso, Cuiabá, MT.

Endereço para correspondência: Prof ${ }^{a}$ Márcia Hueb. Dept ${ }^{\circ}$ de Clínica Médica; Hospital Universitário Júlio Müller; R. L s/n, Bairro Alvorada, 78070-000 Cuiabá, MT, Fax: (065) 322-5426.

Recebido para publicação em 05/06/95. de Leverger, MT, sem história de viagens para fora de Mato Grosso. Apresentava quadro febril, esplenomegalia e pancitopenia. $O$ aspirado de medula óssea mostrava hipocelularidade e plasmócitos abundantes, porém foi negativo para leishmânia. A paciente piorou progressivamente, evoluindo para o óbito. O diagnóstico de LV foi confirmado pelo exame histopatológico post mortem do fígado.

Ainda em 1992, diagnosticou-se o terceiro caso da doença, em um jovem de 15 anos, masculino, natural de Diamantino, MT e residente na serra de São Vicente, área rural distante aproximadamente $70 \mathrm{~km}$ de Cuiabá. Também apresentava esplenomegalia, hipergamaglobulinemia e pancitopenia, e a pesquisa de Leishmania em aspirado de medula óssea resultou positiva. Após a instituição da terapêutica, o paciente evoluiu para cura clínica.

O último caso ocorreu em 1994 e tratava-se de uma criança de 3 anos e 6 meses de idade, sexo masculino, natural de Cuiabá e procedente de zona rural do município vizinho, de Nossa Senhora do Livramento, MT. O paciente apresentava febre, hepatoesplenomegalia, anemia, leucopenia e hipergamaglobulinemia. O diagnóstico de LV foi feito pela visualização do parasita em aspirado de medula óssea, após o qual a criança recebeu tratamento, com melhora completa do quadro.

Atualmente, a LV ocorre em pelo menos 17 estados brasileiros, distribuídos pelas regiões Nordeste, Sudeste, Norte e Centro-Oeste ${ }^{69}$. A presença de casos autóctones de LV em Mato Grosso indica a possibilidade de um foco de transmissão em surgimento. Nesse Estado, o afluxo de migrantes de várias localidades brasileiras ocorreu a partir da década de 70, e é possível que a expansão da doença para essa área, anteriormente indene, esteja associada à migração de indivíduos procedentes de áreas endêmicas, muitas vezes acompanhados de 
Comunicação. Hueb M, Assis SB, Guimarães EED, Rosa DL, Fontes CJF. Ocorrência de transmissāo autóctone de leishmaniose visceral em Mato Grosso. Revista da Sociedade Brasileira de Medicina Tropical 29:281-282, mai-jun, 1996.

seus cães infectados, dando oportunidade ao estabelecimento de novos focos da $\mathrm{LV}^{3}$. Em outras regiôes brasileiras têm sido relatadas situações semelhantes, com surgimento de novos focos da doença, como descrito em Roraima $^{15}$, assim como a urbanização da doença ocorrida em Terezina ${ }^{2}$, Belo Horizonte ${ }^{\ddagger}$ e Rio de Janeiro. ${ }^{8}$ O fato da doença ter se manifestado predominantemente em indivíduos adultos, corrobora a possibilidade de introdução recente da $L V$ na região, uma vez que em áreas de transmissão estabelecida esta protozoose predomina em grupos etários mais baixos ${ }^{10}$.

É importante enfatizar que os casos aqui relatados são de indivíduos procedentes de diferentes municípios matogrossenses, porém situados na área de abrangência da região Centro-Sul do Estado, a mais populosa e, portanto, com risco maior de rápida disseminação. A observação dos casos relatados conduz à necessidade de uma investigação epidemiológica ampla, para detecção de casos humanos e caninos, assim como para a identificação de insetos vetores. Somente a partir desse estudo será possivel confirmar o foco de transmissão e implementar açōes precoces e eficazes para bloquear o ciclo da doença no Estado.

\section{REFERÊNCIAS BIBLIOGRÁFICAS}

1. Castellón EG, Domingos ED. On the focus of kalaazar in the State of Roraima, Brazil. Memórias do Institulo Oswaldo Cruz 86:375,1991.

2. Costa CHN, Pereira HF, Araújo MV. Epidemia de leishmaniose visceral no Estado de Piauí, Brasil, 1980-1986. Revista de Saúde Pública 24:361-372, 1990.
3. Deane LM, Deane MP. Observações preliminares sobre a importância comparativa do homem, do cão e da raposa (Lycalopex vetulus) como reservatórios da Leishmania donovani, em área endêmica de calazar no Ceará. O Hospital 48:79. 98,1955

4. Genaro O, Costa CA, Willians P, Silva JE, Rocha NM, Lima SL, Mayrink W. Ocorrència de calazar em área urbana da grande Belo Horizonte, MG. Revista da Sociedade Brasileira de Medicina Tropical 23:121, 1990.

5. Guerra JAO, Fé NF, Barros MLB, Clenange FCR, Lima CS, Guerra MVF. Leishmaniose visceral em Roraima - Casos registrado de 1989 a 1994. Revista da Sociedade Brasileira de Medicina Tropical 28 (supl 1):142, 1995.

6. Lacerda MM. The Brazilian leishmaniasis control program. Memórias do Instituto Oswaldo Cruz 89:489-495, 1994.

7. Marzochi MCA, Marzochi KBF. Tegumentary and visceral leishmaniasis in Brazil - emerging anthropozoonosis and possibilities for their control. Cadernos de Saúde Pública 10 (supl II):359-375, 1994.

8. Marzochi MCA, Marzochi KBF, Carvalho RW. Visceral leishmaniasis in Rio de Janeiro. Parasitology Today 10:37-40, 1994.

9. Monteiro PS, Lacerda MM, Arias JR. Controle da leishmaniose visceral no Brasil. Revista da Sociedade Brasileira de Medicina Tropical 27 (supl II):67-72, 1991.

10. Organización Mundial de la Salud. La lucha contra a las leishmaniasis. Serie de informes técnicos 793. OMS, Espanha, 1990. 